\title{
Test and Analysis of a Buckling-Critical Large-Scale Sandwich Composite Cylinder
}

\author{
Marc R. Schultz ${ }^{1}$ and David W. Sleight ${ }^{2}$ \\ NASA Langley Research Center, Hampton, VA 23681, USA \\ Nathaniel W. Gardner ${ }^{3}$ \\ Analytical Services \& Materials, Inc., Hampton, VA 23681, USA \\ Michelle T. Rudd ${ }^{4}$ \\ NASA Marshall Space Flight Center, Huntsville, AL 35812, USA \\ Mark W. Hilburger ${ }^{5}$ \\ NASA Langley Research Center, Hampton, VA 23681, USA \\ Tod E. Palm ${ }^{6}$ \\ Northrop Grumman Corporation, Redondo Beach, CA 90278, USA \\ and \\ Nathan J. Oldfield ${ }^{7}$ \\ Northrop Grumman Corporation, Huntsville, AL 35806, USA
}

\begin{abstract}
Structural stability is an important design consideration for launch-vehicle shell structures and it is well known that the buckling response of such shell structures can be very sensitive to small geometric imperfections. As part of an effort to develop new buckling design guidelines for sandwich composite cylindrical shells, an 8-ft-diameter honeycomb-core sandwich composite cylinder was tested under pure axial compression to failure. The results from this test are compared with finite-element-analysis predictions and overall agreement was very good. In particular, the predicted buckling load was within $1 \%$ of the test and the character of the response matched well. However, it was found that the agreement could be improved by including composite material nonlinearity in the analysis, and that the predicted buckling initiation site was sensitive to the addition of small bending loads to the primary axial load in analyses.
\end{abstract}

\footnotetext{
AFT $\quad=$ Aft (bottom) end of test article

CTA8.1 $=$ The considered 8-ft-diameter sandwich composite test article

DIC $\quad$ Digital image correlation

$E_{1}, E_{2}, E_{3} \quad=$ Lamina fiber-direction stiffness, in-plane matrix-direction stiffness, and through-thickness matrix-direction stiffness, respectively
}

\footnotetext{
${ }^{1}$ Research Aerospace Engineer, Structural Mechanics and Concepts Branch, 8 West Taylor St., Mail Stop 190, and AIAA Senior Member.

${ }^{2}$ Aerospace Engineer, Structural and Thermal Systems Branch, 1 North Dryden St., MS 431, AIAA Senior Member.

${ }^{3}$ Digital Image Correlation Specialist, Structural Materials and Concepts Branch, 8 West Taylor St., Mail Stop 190.

${ }^{4}$ Aerospace Engineer, Dynamics, Loads \& Strength Branch, 4600 Rideout Rd., EV31, AIAA Member.

${ }^{5}$ Senior Research Engineer, Structural Mechanics and Concepts Branch, 8 West Taylor St., Mail Stop 190, and AIAA Senior Member.

${ }^{6}$ Manager, Airframe Technology Development, One Space Park.

${ }^{7}$ Design Engineer, Responsive Space Access, 301 Voyager Way, M/S UAL312-128D, and AIAA Member.
}

American Institute of Aeronautics and Astronautics 


\begin{tabular}{ll}
$G_{12}, G_{13}, G_{23}$ & $=$ Material-direction shear stiffnesses \\
FEA & $=$ Finite-element analysis \\
FEM & $=$ Finite-element model \\
FWD & $=$ Forward (top) end of test article \\
KDF & $=$ Buckling knockdown factor \\
IML & $=$ Inner mold line \\
LaRC & $=$ NASA Langley Research Center \\
MSFC & $=$ NASA Marshall Space Flight Center \\
NESC & $=$ NASA Engineering and Safety Center \\
NDE & $=$ Nondestructive evaluation \\
NGC & $=$ Northrop Grumman Corporation \\
OML & $=$ Outer mold line \\
SBKF & $=$ Shell Buckling Knockdown Factor Project \\
UMAT & $=$ Abaqus user-defined material subroutine \\
$\varepsilon_{1}$ & $=$ Fiber-direction strain \\
$v_{12}, v_{13}, v_{23}$ & $=$ Material-direction Poisson's Ratios \\
$\sigma_{1}$ & $=$ Fiber-direction stress \\
Subscripts & \\
\hline 1 & $=$ In-plane fiber direction \\
2 & $=$ In-plane matrix direction \\
3 & $=$ Thickness direction \\
T & $=$ Indicates total laminate stacking sequence
\end{tabular}

\section{Introduction}

tructural stability is an important consideration in the design of launch-vehicle shell structures such as cryotanks, intertanks, interstages, skirts, payload adapters, and fairings. The buckling response of shell structures can also be very sensitive to small geometric and loading imperfections, so the buckling loads seen in practice can be significantly lower than the theoretical buckling load of a geometrically perfect, uniformly loaded structure. Therefore, it is important to understand the buckling response of these structures, and it is also important to have validated guidelines for use during design. In the 1960s, NASA published a series of empirically derived buckling design recommendations that have become widely used throughout the world. ${ }^{1,2,3}$ However, these recommendations are generally considered overly conservative, and they were not developed for modern launch-vehicle configurations, materials, or manufacturing methods. For example, uncertainty about the applicability of such recommendations for composite structures comes from the observation that few, if any, composite shells were tested in their development. In 2007, the NASA Engineering and Safety Center (NESC) established the Shell Buckling Knockdown Factor Project (SBKF) to address some of these shortcomings. In particular, the primary objective of SBKF is to develop new analysis-based buckling design guidelines for selected classes of metallic and composite cylindrical shells. ${ }^{4}$ Experimental validation testing is being performed at the subcomponent, panel, and cylinder levels as part of this development. The test, analysis, and test-analysis correlation of the first large-scale SBKF composite validation test article is discussed herein. This test article, designated CTA8.1, was an 8-ft-diameter honeycomb-core sandwich composite cylinder that was built by the Northrop Grumman Corporation (NGC) as part of a collaborative effort with SBKF.

The details of the test facility and test article are given in Section II. Section III provides detailed descriptions of the pretest predictions, the experimentally observed test results, and the test-analysis correlation. A discussion of the results of this test in the context of design, and concluding remarks are given in Sections IV and V, respectively.

\section{Testing Details}

\section{A. Test Facility}

The facility used to test CTA8.1 is a specially built buckling test facility at NASA Marshall Space flight Center (MSFC) that had been previously used to test eight 8-ft-diameter stiffened metallic test articles (see ref. 5). The test facility is self-reacting, and as seen in Figure 1, consists of top and bottom load-introduction structures connected by eight load lines that include hydraulic actuators and load cells. The facility is capable of applying pure compression up to $1,500,000 \mathrm{lb}$, pure tension up to $80,000 \mathrm{lb}$, combined axial and bending loads, and internal pressure up to $10 \mathrm{psi}$.

American Institute of Aeronautics and Astronautics 
The hydraulic actuators apply equal tension in each of the load lines to load the test article in pure compression, whereas the load lines are differentially loaded to apply combined compression and bending loads.

\section{B. Test Article}

The NASA-designed CTA8.1 test article was a honeycomb-core sandwich composite cylinder manufactured by NGC as a manufacturing development unit. Test article CTA8.1 was an 8-ft-diameter, 120-in.-long honeycomb-core sandwich composite cylinder constructed with Cytec IM7/MTM45 faces and Hexcel KOREX core that was manufactured in a proprietary out-of-autoclave process. In each step described below, the part was cured at elevated temperature in an oven with $1 \mathrm{~atm}$ pressure provided by a vacuum bag. In particular, the inner mold line (IML) facesheet was applied by hand laying and curing 145 gsm IM7/MTM45 unidirectional prepreg plies on a cylindrical tool. After debagging, Cytec FM 300-2K 0.08 psf film adhesive, BGF Industries Style 1653 fiberglass scrim, and KOREX-1/8-4.5 core with the ribbon direction axially aligned were applied by hand with $3 \mathrm{M} \mathrm{AF} 3024$ foaming adhesive along the core joints; this facesheet and core assembly was then cured. To apply the outer mold line (OML) facesheet, Style 1653 scrim, FM 300-2K film adhesive, and IM7/MTM45 prepreg plies were hand laid, bagged, and cured. In the acreage region, the axially stiff 7 -ply facesheets had a total layup of $[45 /-45 / 0 / 90 / 0 /-45 / 45]_{\mathrm{T}}$, where the " $\mathrm{T}$ " indicates total laminate stacking sequence, and the core was 0.25 -in. thick. Additionally, padups (doublers) were secondarily bonded to each end to aid in the load introduction. Specifically, six-ply padups of 145 gsm IM7/MTM45 prepreg were hand laid and cobonded to both ends of the cylinder on the IML and OML using FM 300-2K 0.08 psf film adhesive. These padups were bagged and cured in two steps - first the aft (AFT) padups, then the forward (FWD) padups. In the first 14 in. from the end, the padups were six plies; starting from the precured barrel, the layup was [45/-45/45/45/-45/45]T. Two plies in each padup were terminated $14 \mathrm{in}$. from the ends and the padup layup became $[45 /-45 /-45 / 45]_{\mathrm{T}}$. Two more plies were terminated $18 \mathrm{in}$. from the ends and the padup layup became $[-45 / 45]_{\mathrm{T}}$. The final two plies in each padup were terminated $20 \mathrm{in}$. from the ends. Finally, the test article underwent a free-standing postcure in an oven.

After fabrication (and the repairs described below) was complete, the CTA8.1 ends were machined flat and parallel. To interface with the test facility, pi-cross-section aluminum end rings were mounted to the test article and then bolted to the test facility. The test article was potted in the end-ring channels using Unisorb Standard V-100 epoxy grout, and 18 radial bolts were inserted through the end rings and cylinder wall as a failsafe measure in case the epoxy potting failed during testing.

\section{Nondestructive Evaluation}

A number of nondestructive evaluation (NDE) techniques were used to determine the as-manufactured state of CTA8.1. These techniques included visual inspection, flash thermography (see for example ref. 6), and vacuum shearography (see for example ref. 7). Several flaws in the test article were found using these techniques. In particular, visual inspection revealed several areas of dry fiber on the IML. Flash thermography revealed a significant number of voids in the bond line of both the IML and OML FWD padups. Finally, vacuum shearography indicated a large (approximately 10 -in. by 15 -in.) delamination in the IML AFT bond line.

Structured light scanning (see for example ref. 8) was used to measure the as-built geometry of the inner mold line (IML) and outer mold line (OML) in the same coordinate system. These measurements were used to calculate the thickness. The measured midsurface radial imperfections (deviations from a best-fit cylinder) and the calculated thickness are shown in Figure 2. In Figure 2a, it is seen that the maximum radial imperfections were about \pm 0.1 in. and that the maximum inward radial imperfections were clustered near $0^{\circ}$ and $180^{\circ}$. In Figure $2 \mathrm{~b}$, it is seen that the top and bottom of the cylinder had the greatest thickness because of the secondarily bonded padups on each end. The thickness-variation pattern in the acreage of CTA8.1 appeared to be correlated to the core layout, and could be an artifact of using core sheets with slightly different thicknesses.

\section{Repairs}

Based on the results of the NDE, several repairs were deemed necessary to address the flaw indications found. First, the dry fiber regions on the IML were repaired using Epon 828 room-temperature adhesive, which was bagged and cured at pressure.

To address the voids found in the FWD padup, a series of repairs were attempted on the FWD padup, but they were ultimately unsuccessful. Therefore, newly designed padups were applied aft of the original FWD padup, and the barrel was shortened by $20 \mathrm{in}$. in order to remove the original padup region; the as-tested length of CTA8.1 was therefore $100 \mathrm{in}$. These padups were similar to the original padups in that they are nominally 20 -in. long with the same ply-drop approach. However, the new padups consist of three AS4/8552 8-harness-satin fabric prepreg plies (370 gsm, 0.014 in. thick) with a $[45 /-45 / 45]_{\mathrm{T}}$ stacking sequence. To essentially match the original padup, the middle $-45^{\circ}$ ply

American Institute of Aeronautics and Astronautics 
was terminated 14 in. from the FWD end, the $45^{\circ}$ ply closest to the barrel skin was terminated 18 in. from the FWD end, and the final ply was terminated 20 in. from the FWD end. The new FWD padups were cobonded in an oven as previously described.

The large disbond in the AFT padup was repaired by removing the disbonded region and applying a scarf repair with the AS4/8552 prepreg fabric and FM 200K film adhesive. Because the disbond occurred over all three padup ply drops, the new fabric padup also had ply drops. In the thickest region (most aft), the fabric padup had a $[45 /-45 / 45]_{\mathrm{T}}$ stacking sequence. After the first ply drop, the stacking sequence was $\left[45_{2}\right]_{\mathrm{T}}$, and closest to the undamaged region the new padup repair had a single $45^{\circ}$ fabric ply. The original padup was removed with a 0.5 -in. scarf taper, so the fabric padup repair plies were appropriately sized to reflect this taper. The topmost ply was oversized by approximately 0.5 in. all around, except it was not extended past the original padup into the acreage region. The scarf repair was bagged and cured using essentially the same process, but with heat from a local strip heater.

\section{Instrumentation}

Instrumentation used to monitor the structural response during loading included: 28 electrical displacement transducers, 256 electrical-resistance strain gages, approximately 16,000 fiber-optic strain sensor locations, ${ }^{9}$ eight lowspeed digital image correlation (DIC) photogrammetry systems ${ }^{10}$ to measure full-field strains and displacements on the entire OML, and six high-speed DIC systems to measure OML strains and displacements during the dynamic buckling event. Additionally, several microphones and standard-rate video cameras were used to monitor the testing.

\section{Test and Analysis Results}

After CTA8.1 was mounted into the test facility, a series of subcritical load sequences were performed as system checks, and to interrogate the structural response of the test article under different loading conditions. These subcritical load sequences included varying levels of axial compression, and combined compression and bending with the maximum compression at different circumferential positions. The final load case for CTA8.1 was axial compression to failure.

\section{A. Finite-Element Analysis}

Pretest predictions for the response of CTA8.1 were obtained using a finite-element model (FEM) developed in Patran for a solution using the Abaqus 6.14 general-purpose finite-element analysis (FEA) code. ${ }^{11}$ The FEM of CTA8.1 included a representation of the entire test assembly, including the upper and lower load spiders and struts, upper and lower transition sections, test-article end rings, and CTA8.1 itself (Figure 3). The test article was modeled with S4 four-noded general-purpose shell elements, and the load-introduction structure was modeled with a combination of S4 shell and B31 shear-flexible beam elements for a total of 167,088 elements and 169,236 nodes. A convergence study was performed on the test-article FEM and it was shown that with four times the number of elements, the predicted buckling response was qualitatively similar and the buckling load was within $0.1 \%$.

To obtain pretest predictions, the as-measured test-article imperfections were used to modify the geometrically perfect nominal geometry of the test-article mesh to accurately represent the as-built geometrically imperfect test article. A user-written program was used to read in the measured white light scan data, and then radially adjust or perturb the midsurface geometry of the finite-element mesh at each node location. The measured thickness variations in CTA8.1 were presumed to be due to variations in the core thickness, and were modeled by modifying the FEM core thickness in the composite layup properties on an element-by-element basis.

The load was introduced into the structure by applying eight point loads at the ends of beams representing the load lines (red arrows in Figure 3) in the test configuration, and holding the bottom loading spider fixed at its base. For the pretest analyses of the subcritical load sequences, nonlinear static analyses were performed using load control on the CTA8.1 FEM. For the pretest analyses of the final load sequence to buckling failure, a combination nonlinear static and nonlinear transient analysis was performed using displacement control. The nonlinear static analysis simulated loading up to $80 \%$ of the predicted buckling load. The nonlinear transient analysis continued the loading simulation from this point through buckling and into the postbuckling range. The predicted buckling load was determined by a load drop in a plotted load-deflection curve.

Additional analysis (and observations during test) indicated that the dry-fiber and AFT padup-patch repairs had insignificant effect on the structural response of CTA8.1 under load so they will not be discussed in the context of the test and analysis correlation. However, the test predictions were made with FEMs that included the FWD fabric padups.

American Institute of Aeronautics and Astronautics 


\section{B. Test-Analysis Correlation}

1. With Pretest Predictions

Since the test article was fabricated as part of a manufacturing development effort, material properties were not well known prior to testing; pretest material property testing was planned, but was ultimately unsuccessful due to testing difficulties. Therefore a combination of assumed and vendor-provided properties were used for the core and assumed IM7/8552 properties were used as generic material properties for the faces because IM7/MTM45 properties were not available (Table 1). During the initial subcritical load cases, the character of the response agreed with predictions, but the axial stiffness of the barrel was significantly under predicted. Therefore, these initial subcritical tests were treated as large-scale material-property calibration tests, and the in-plane stiffnesses $\left(E_{1}, E_{2}\right)$ were increased by $8.71 \%$ in order to better match the test stiffness, and the failure-load-sequence analysis was rerun. The predictions presented herein are from this rerun analysis with the increased stiffnesses, and the modified ply properties are shown in Table 1. During the initial subcritical load cases, it was also observed that the test article was settling in the end rings in a series of distinct events. This settling was verified using DIC and fiber-optic strain sensors and appeared to be a failure of the bond between the test article and the potting epoxy (ref. 9). Settling events were observed each time the test article was placed under previously unseen load levels, but not when it was subsequently loaded to the same load level. Since this settling was not modeled in the analysis, and can affect end-shortening measurements from the end rings, the test-article shortening is reported herein over the test section (the central 80.4 in.) as measured using DIC.

The predicted and measured load vs. axial test-section displacement for the axial compression failure load case are shown in Figure 4. It is seen that the initial load vs. displacement responses were essentially linear to a peak load at which point sudden global buckling occurs. Even though the FEA stiffnesses were adjusted to match the subcritical tests, there was noticeable nonlinearity in the experimental load vs. displacement response that was not predicted. In addition to good stiffness agreement, the predicted buckling load of $864,600 \mathrm{lb}$ and measured buckling load of 856,900 $\mathrm{lb}$ agreed within $1 \%$.

The predicted and measured radial displacements at 458,200 lb (approximately $50 \%$ of buckling load) are shown in Figure 5. In this figure, it is seen that the radial displacements are significantly nonuniform even though the loaddisplacement relation was essentially linear prior to buckling. Notice that the magnitudes of the predicted and measured radial displacements are similar, and that all of the major features seen in the test were also present in the pretest predictions. The features of primary importance were a number of inward dimples that had lower radial displacements than most of the test article. As loading was increased, these inward dimples grew in amplitude with some growing faster than others, especially near the buckling load. As the load approached the buckling load, the global buckling initiated with a loss of stability at one of these dimples. This buckling progression was predicted by the FEA, but was also seen in the test with low-speed and high-speed DIC. However, the specific predicted buckling initiation site was different than that seen in the test. Figure 6 shows the predicted and measured radial displacements at incipient failure. The predicted buckling initiation site is indicated in Figure $6 \mathrm{a}$ as the dark blue region at a circumferential location near $305^{\circ}$, and the experimental buckling initiation site is indicated in Figure $6 \mathrm{~b}$ as the dark blue region at a circumferential location near $45^{\circ}$. Immediately after the initiation of buckling in the test, deformations rapidly grew causing a strength failure in the facesheets due to the large-magnitude bending deformations and strains associated with the buckling response; this strength failure quickly propagated around the entire circumference of the cylinder. Because the failure occurred so rapidly, it was important to verify this failure sequence - stability failure leading to strength failure. Figure 7 shows the axial load plotted versus axial strain at the experimental buckling initiation site with the strain measured using the low-speed and high-speed DIC. Considering the low-speed DIC first, it is seen that the curve is initially linear, but as the buckling load is approached, the slope decreases until it is essentially zero, indicating that large changes in strain occur with minimal change in load. The last low-speed DIC data was taken at a load of $856,400 \mathrm{lb}$, which is close to the peak recorded load of $856,900 \mathrm{lb}$, so the high-speed DIC data was plotted with a constant load of $856,400 \mathrm{lb}$ in Figure 7. At the transition between the low-speed and highspeed DIC, the buckling initiation site was under approximately 5,200 $\mu \varepsilon$ axial strain. This was significantly below the average failure strain of $8,400 \mu \varepsilon$ that was measured in posttest edgewise compression testing. Therefore, it was demonstrated that CTA8.1 experienced a loss of stability prior to the strength failure. The test article had little residual load carrying capability after buckling due to this extensive failure.

2. With Posttest Analysis

Despite the generally good agreement between analysis and test for the CTA8.1 failure load sequence, posttest analyses were deemed necessary to explore the differences that were observed. Of particular interest were the stiffness adjustment that was made to the pretest FEA predictions, the slight nonlinearity observed in the experimental prebuckling load vs displacement plot, and the buckling initiation site.

American Institute of Aeronautics and Astronautics 
After the buckling test, specimens were sectioned from the barrel to determine the axial in-plane shell stiffness, including any nonlinear stress-strain response. It has been shown that uniaxial graphite epoxy laminates can show such nonlinear response (e.g., ref. 12). For the posttest testing, 12 edgewise axial compression specimens were cut from three different apparently undamaged locations on CTA8.1. These edgewise compression specimens were tested essentially according to ASTM Standard C $364,{ }^{13}$ but with the procedure modified to include the ASTM Standard D $7137^{14}$ support fixture to prevent panel buckling. Centered back-to-back strain gages were also included to directly measure the stress-strain response. As part of this testing, the facesheet thickness was measured and it was found that the average ply thickness was 0.005679 in. This measured ply thickness is $9.2 \%$ thicker than the nominal ply thickness of 0.0052 in. and helps explain why the observed load vs. end shortening response during the subcritical tests was stiffer than predicted, and therefore necessary to increase the FEM stiffnesses to match the FEA with the subcritical tests.

The edgewise-compression stress-strain curves were also noticeably nonlinear, so a nonlinear material model for the fiber-direction stiffness was developed using these data, presuming that the lamina fiber-direction stiffness, $E_{1}$, was variable stiffness. Because the edgewise compression specimens consisted of sandwich sections with multidirectional facesheets, the nonlinear fiber-direction stiffness could not be measured directly, but was calculated as follows. The axial stress for each edgewise-compression-specimen strain gage was calculated as a function of the measured strain using the measured load and facesheet cross-sectional area. Next, curves were fit to the calculated stress vs. average measured strain (the average of the back-to-back strain gages) for each edgewise-compression specimen. These curves for all samples were then combined to obtain an overall average curve fit for laminate stress vs. strain. The laminate axial secant stiffness was then calculated as a function of strain from the stress-strain curve equation and used to estimate the lamina fiber-direction stiffness, $E_{1}$, required to achieve the laminate secant stiffness as specific values of strain. Specifically, $E_{1}$ was determined using a laminated-plate code with the nominal lamina properties shown in Table 1 for the in-plane matrix-direction stiffness, $E_{2}$, the in-plane shear modulus, $G_{12}$, the inplane Poisson's Ratio, $v_{12}$, a layup of [45/-45/0/90/0/-45/45] $]_{\mathrm{s}}$, and the average ply thickness of $0.005679 \mathrm{in}$. (All axial load was assumed to be carried by the facesheets, so the core was ignored in this analysis.) For each strain level between 0 and $-8,000 \mu \varepsilon$ in increments of $500 \mu \varepsilon$, the value of $E_{1}$ was adjusted until the calculated laminate stiffness matched the experimental secant stiffness previously calculated for that strain. Finally, the fiber-direction stress for the $0^{\circ}$ plies was calculated at each strain level, and a curve was fit to these data to obtain the final stress-strain curve to be used for the fiber direction. For the present work, a second-order polynomial was found to accurately represent the data. Using the procedure described above the fiber-direction stress-strain relationship was calculated to be

$$
\sigma_{1}=\left(20.662 \times 10^{6} \varepsilon_{1}+3.1575 \times 10^{8} \varepsilon_{1}^{2}\right) \mathrm{psi}
$$

where $\sigma_{1}$ is the fiber-direction stress and $\varepsilon_{1}$ is the fiber-direction strain. The variable fiber-direction tangent stiffness, $E_{1}\left(\varepsilon_{1}\right)$, is then

$$
E_{1}\left(\varepsilon_{1}\right)=\left(20.662 \times 10^{6}+6.3150 \times 10^{8} \varepsilon_{1}\right) \mathrm{psi}
$$

A user-defined material subroutine (UMAT) was written for Abaqus so the stress-strain equation (eq. 1) could be used in the CTA8.1 buckling simulations. Using this UMAT, a ply thickness of $0.005679 \mathrm{in}$., and the other nominal properties given in Table 1, the CTA8.1 buckling simulation with no other changes was rerun. The predicted deformation patterns using the nonlinear material model were essentially unchanged from the pretest predictions shown in Figure 5 and Figure 6. However, the predicted buckling load was $845,000 \mathrm{lb}$, slightly smaller, but still within $1.4 \%$ of the experimental buckling load of $856,900 \mathrm{lb}$. The predicted load-displacement response using the nonlinear material model is shown with the measured response from the test in Figure 8. In this figure, it is seen that the nonlinearity in the predicted load-displacement response matches well that of the test response, so it was concluded that that the nonlinear test response was due to material nonlinearity.

It can be seen in Figure 5 that there are number of inward dimples in the test article that could be potential buckling initiation sites, and in Figure 6 that the predicted buckling initiation site was different than the experimental buckling initiation site. However, it was believed that slight loading imperfections could move the site of the buckling initiation site. These loading imperfections could be localized imperfections such as those seen during the settling events or could be more global nonuniformities such as a slight bending moment superimposed on the desired compression loading. The latter, the bending moment imperfection during testing, could be estimated by monitoring the load measured in each of the eight load lines; doing this, it was found that there was a slight bending moment applied to the cylinder. This calculated bending moment at the peak load was relatively small at approximately 40,000 in-lb with

American Institute of Aeronautics and Astronautics 
the maximum compression at the $135^{\circ}$ circumferential position and the minimum compression at the $315^{\circ}$ circumferential position. At the buckling load, this 40,000 in-lb moment would cause approximately $\pm 0.2 \%$ variation in compressive line load in the test article with the highest compression at approximately the $135^{\circ}$ circumferential position. Though it was understood that there were localized load variations in the test article due to fit tolerances at the end interfaces and due to the aforementioned settling events, the effects of loading imperfection on the buckling response of the CTA8.1 were explored through a series of analyses with combined loading consisting of compression and small amounts of bending to try to numerically replicate the location of the experimental buckling initiation site. In these analyses, two bending moment directions were considered: the bending load was either oriented such that the area of maximum compression was at the $135^{\circ}$ circumferential position (as was measured from the test) and the minimum compression was at the $315^{\circ}$ circumferential position so that the original predicted site of buckling initiation would be near the minimum compression, or the bending load was oriented such that the maximum compression was at the $45^{\circ}$ circumferential location, the location of the experimental buckling initiation site. Analyses with bending moments with magnitudes equivalent to $1 \%, 2 \%$, and $3 \%$ of the axial compression were performed. That is, these bending moments induced line-load variations of $1 \%, 2 \%$, and $3 \%$ of the mean line load. Results from these analyses are shown in Table 2, where it is shown that the considered loading imperfections were predicted to increase the buckling load over pure axial compression loading. However, these small bending moments did not change the predicted buckling loads significantly - for all of these combined loading cases, the predicted buckling load was within $1.4 \%$ below and $0.35 \%$ above the test failure load. The addition of these bending moments did not change the predicted radial-displacement pattern significantly, but for certain cases did change the buckling initiation site. For example, it was found that bending moments equivalent to $1 \%$ and $2 \%$ of the compression load did not shift the predicted buckling initiation site. However, it was found that a bending moment of $3 \%$ in the $135^{\circ}$ direction shifted the predicted buckling initiation away from $305^{\circ}$ and to a $206^{\circ}$ circumferential location, and a bending moment of $3 \%$ in the $45^{\circ}$ direction shifted the predicted buckling initiation site from $305^{\circ}$ to the $45^{\circ}$ circumferential location that was the test buckling initiation site. Predicted radial displacements for analyses with $3 \%$ bending applied toward $135^{\circ}$ and $45^{\circ}$ are shown in Figure 9. Comparing the contour plots in Figure 9 with the pretest predicted contour in Figure 6a, it is seen that the radial-displacement patterns are qualitatively similar, but that the relative magnitudes of the dimples and buckling initiation sites are different. Based on these numerical results, it is shown that the right combination of small loading imperfections could shift the buckling initiation site. In experimental testing, these loading imperfections could be a combination of fit-up tolerances, variations in load due to slipping in the end rings as was described earlier, and global bending loads.

\section{Discussion of Results in the Context of Design}

The buckling imperfection sensitivity of shell structures is typically accounted for in design by multiplying the predicted buckling load of the geometrically perfect shell by a design factor called a buckling knockdown factor (KDF). The current NASA design guideline for buckling of cylindrical shells, SP-8007, ${ }^{1}$ provides recommendations for orthotropic cylinders and for isotropic sandwich cylinders, but it does not provide recommendations for sandwich composite cylinders. The orthotropic SP-8007 KDF calculated for CTA8.1 is 0.61. For CTA8.1, the normalized buckling load (test buckling load divided by predicted perfect eigenvalue bucking load) was 0.87 . Though this normalized buckling load is not to be used as a design recommendation, comparison with the SP-8007 KDF indicates that there may be significant conservatism in the current recommendations for modern launch-vehicle structures.

\section{Concluding Remarks}

Buckling is a major design driver for many launch-vehicle shell structures. Thus, it is important to understand the buckling response of such structures. Therefore, the NASA Engineering and Safety Center (NESC) Shell Buckling Knockdown Factor Project (SBKF) is working to revise the decades-old NASA buckling design guidelines for selected classes of metallic and composite shell structures and provide new analysis-based buckling design guidelines. A key part of this effort is the testing of large-scale metallic and composite buckling test articles. Herein was presented a discussion of the first such SBKF composite test article, an 8-ft-diameter honeycomb-core sandwich composite cylinder loaded in pure axial compression to failure. Overall, excellent agreement between test and finite-element predictions was found. Specifically, the experimental and predicted buckling loads were within $1 \%$ and the character of the buckling response were similar. However, nonlinearity in the experimental load versus displacement response was not initially captured by the analysis, and the locations of the experimental and predicted buckling initiation sites were different. It was found that by including experimentally derived material nonlinearity in the finite-element analysis allowed the predictions to match the load-displacement response. Additionally, it was shown through analysis

American Institute of Aeronautics and Astronautics 
that small loading imperfections could move the predicted buckling initiation site to the experimental buckling initiation site without changing the bucking load significantly.

\section{Acknowledgments}

This work was conducted as part of the NASA Engineering and Safety Center (NESC) Shell Buckling Knockdown Factor Project, NESC assessment number 07-010-E. The CTA8.1 test article discussed herein was provided by Northrop Grumman Corporation. Dawson Vincent, now of Griffon Aerospace, and Allison Quesenbery, now of Teledyne Brown Engineering, were instrumental in the fabrication and repair of CTA8.1, respectively. The testing was performed under the direction of Lucas Day by the Structural Strength Test Group (ET30) at MSFC. Dr. Waddy Haynie and Andrew Lovejoy (both NASA Langley Research Center (LaRC)) also contributed significantly to testing activities. The authors would also like to thank Dr. Arunkumar Satyanarayana (LaRC) his work in helping to design the test article and in developing the nonlinear material user subroutine, and Micheal Lindell (LaRC) for his work in postprocessing data and developing the nonlinear material model. Francisco Peña, Dr. W. Lance Richards, Allen Parker, and Anthony Piazza from NASA Armstrong Flight Research Center designed, installed, and operated the fiberoptic strain sensing system, and contributed significantly to the understanding of the structural response of CTA8.1, particularly the load-ring settling.

\section{References}

${ }^{1}$ Weingarten, V.I., Seide, P., and Peterson, J.P., "Buckling of Thin-Walled Circular Cylinders," NASA Space Vehicle Design Criteria, NASA SP-8007, September 1965 (Revised 1968).

${ }^{2}$ Weingarten, V.I. and Seide, P., "Buckling of Thin-Walled Truncated Cones," NASA Space Vehicle Design Criteria, NASA SP-8019, September 1968.

${ }^{3}$ Weingarten, V.I. and Seide, P., "Buckling of Thin-Walled Doubly Curved Shells," NASA Space Vehicle Design Criteria, NASA SP-8032, August 1969.

${ }^{4}$ Hilburger M.W., "Developing the Next Generation Shell Buckling Design Factors and Technologies," Proceedings of the $53^{\text {rd }}$ AIAA/ASME/ASCE/AHS/ASC Structures, Structural Dynamics and Materials Conference, AIAA paper no. 2012-1686, Honolulu, HI, April 2012.

${ }^{5}$ Hilburger M.W., Waters, W.A., Jr., and Haynie, W.T., "Buckling Test Results from the 8-Foot-Diameter Orthogrid-Stiffened Cylinder Test Article TA01," NASA/TP-2015-218785, August 2015.

${ }^{6}$ ASTM Standard E2582-07, "Standard Practice for Infrared Flash Thermography of Composite Panels and Repair Patches Used in Aerospace Applications," ASTM International, West Conshohocken, PA, 2014.

${ }^{7}$ ASTM Standard E2581, "Standard Practice for Shearography of Polymer Matrix Composites and Sandwich Core Materials in Aerospace Applications," ASTM International, West Conshohocken, PA, 2014.

${ }^{8}$ Alexander, B.F. and Ng, K.C., "3D Shape measurement by active triangulation using an array of coded light stripes," SPIE: Optics, Illumination and Image Sensing for Machine Vision II, Vol. 850, 1987, pp. 199-209.

${ }^{9}$ Pena, F., Richards, W.L.; Parker, A.R., Piazza, A., Schultz, M.R., Rudd, M.T., Gardner, N.G., and Hilburger, M.W., "Implementation of Fiber Optic Sensing System on Sandwich Composite Cylinder Buckling Test," Proceedings of the 58 ${ }^{\text {th }}$ AIAA/ASME/ASCE/AHS/ASC Structures, Structural Dynamics \& Materials Conference, Orlando, FL, January 2018 (submitted for publication).

${ }^{10}$ Sutton, M.A., Orteu, J.-J., and Schreier, H.W., Image Correlation for Shape Motion and Deformation Measurements: Basic Concepts, Theory and Applications, Springer, New York, 2009.

${ }^{11}$ Abaqus/Standard, Software Package, Ver. 6.14, Dassault Systèmes, Waltham, MA, 2014.

${ }^{12}$ Murphey, T.W., Sanford, G.E., and Grigoriev, M.M., "Nonlinear Elastic Constitutive Modeling of Large Strains in Carbon Fiber Composite Flexures," Proceedings of the $16^{\text {th }}$ International Conference on Composite Structures (ICCS16), edited by A.J.M. Ferreira, FEUP, Porto, Portugal, 2011.

${ }^{13}$ ASTM Standard C364/C364M-07, Standard Test Method for Edgewise Compressive Strength of Sandwich Constructions, ASTM International, West Conshohocken, PA, 2007 (Reapproved 2012).

${ }^{14}$ ASTM Standard D7137/D7137M-12, Standard Test Method for Compressive Residual Strength Properties of Damaged Polymer Matrix Composite Plates, ASTM International, West Conshohocken, PA, 2012. 
Table 1. Ply and core properties.

\begin{tabular}{|c|c|c|c|c|c|}
\hline Property & $\begin{array}{c}\text { Assumed } \\
\text { IM7/ MTM45 }\end{array}$ & $\begin{array}{c}\text { AS4/8552 } \\
\text { Fabric }\end{array}$ & $\begin{array}{l}\text { Pretest Modified } \\
\text { IM7/MTM45 }\end{array}$ & $\begin{array}{c}\text { Posttest Modified } \\
\text { IM7/MTM45 }\end{array}$ & Core \\
\hline Thickness (in.) & 0.0052 & 0.014 in. & 0.0052 & 0.005679 & 0.25 \\
\hline $\begin{array}{c}\text { Density } \\
\left(1 \mathrm{~b}-\mathrm{s}^{2}-\mathrm{in}^{-4}\right)\end{array}$ & $110.327 \times 10^{-6}$ & $147.6 \times 10^{-6}$ & $110.327 \times 10^{-6}$ & $110.327 \times 10^{-6}$ & $6.729 \times 10^{-6}$ \\
\hline$E_{1}(\mathrm{psi})$ & $20.00 \times 10^{6}$ & $9.4 \times 10^{6}$ & $21.7434 \times 10^{6}$ & $\begin{array}{l}20.662 \times 10^{6}+ \\
6.3150 \times 10^{8} \varepsilon_{1}\end{array}$ & 50. \\
\hline$E_{2}(\mathrm{psi})$ & $1.25 \times 10^{6}$ & $9.4 \times 10^{6}$ & $1.35896 \times 10^{6}$ & $1.25 \times 10^{6}$ & 38. \\
\hline$E_{3}(\mathrm{psi})$ & 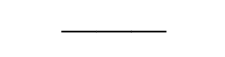 & & & & $60 . \times 10^{3}$ \\
\hline$v_{12}$ & 0.36 & 0.044 & 0.36 & 0.36 & 0.45 \\
\hline$v_{13}$ & & & & & 0.0001 \\
\hline$v_{23}$ & - & & $\longrightarrow$ & 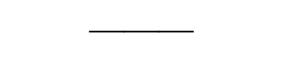 & 0.0001 \\
\hline$G_{12}(\mathrm{psi})$ & $770 \times 10^{3}$ & $720 \times 10^{3}$ & $770 \times 10^{3}$ & $770 \times 10^{3}$ & 17.5 \\
\hline$G_{13}(\mathrm{psi})$ & $770 \times 10^{3}$ & $720 \times 10^{3}$ & $770 \times 10^{3}$ & $770 \times 10^{3}$ & $29.5 \times 10^{3}$ \\
\hline$G_{23}(p s i)$ & $385 \times 10^{3}$ & $720 \times 10^{3}$ & $385 \times 10^{3}$ & $385 \times 10^{3}$ & $12.0 \times 10^{3}$ \\
\hline
\end{tabular}

Table 2. Summary of buckling loads and site.

\begin{tabular}{|c|c|c|c|}
\hline Case & Buckling load (lb) & $\begin{array}{c}\text { Buckling load } \\
\text { difference from test }\end{array}$ & $\begin{array}{l}\text { Circumferential site of } \\
\text { buckling initiation }\end{array}$ \\
\hline Test & 856,900 & $\longrightarrow$ & $45^{\circ}$ \\
\hline Pretest prediction & 864,600 & $0.90 \%$ & $305^{\circ}$ \\
\hline $\begin{array}{l}\text { Nonlinear posttest prediction } \\
\text { (pure compression) }\end{array}$ & 845,000 & $-1.4 \%$ & $305^{\circ}$ \\
\hline $\begin{array}{l}\text { Nonlinear posttest prediction } \\
\text { (with } 1 \% \text { bending toward } 135^{\circ} \text { ) }\end{array}$ & 852,200 & $-0.55 \%$ & $305^{\circ}$ \\
\hline $\begin{array}{l}\text { Nonlinear posttest prediction } \\
\text { (with } 1 \% \text { bending toward } 45^{\circ} \text { ) }\end{array}$ & 846,300 & $-1.2 \%$ & $305^{\circ}$ \\
\hline $\begin{array}{l}\text { Nonlinear posttest prediction } \\
\text { (with } 2 \% \text { bending toward } 135^{\circ} \text { ) }\end{array}$ & 859,900 & $0.35 \%$ & $305^{\circ}$ \\
\hline $\begin{array}{l}\text { Nonlinear posttest prediction } \\
\text { (with } 2 \% \text { bending toward } 45^{\circ} \text { ) }\end{array}$ & 848,300 & $-1.0 \%$ & $305^{\circ}$ \\
\hline $\begin{array}{l}\text { Nonlinear posttest prediction } \\
\text { (with } 3 \% \text { bending toward } 135^{\circ} \text { ) }\end{array}$ & 857,100 & $0.02 \%$ & $206^{\circ}$ \\
\hline $\begin{array}{l}\text { Nonlinear posttest prediction } \\
\text { (with } 3 \% \text { bending toward } 45^{\circ} \text { ) }\end{array}$ & 848,800 & $-0.95 \%$ & $45^{\circ}$ \\
\hline
\end{tabular}




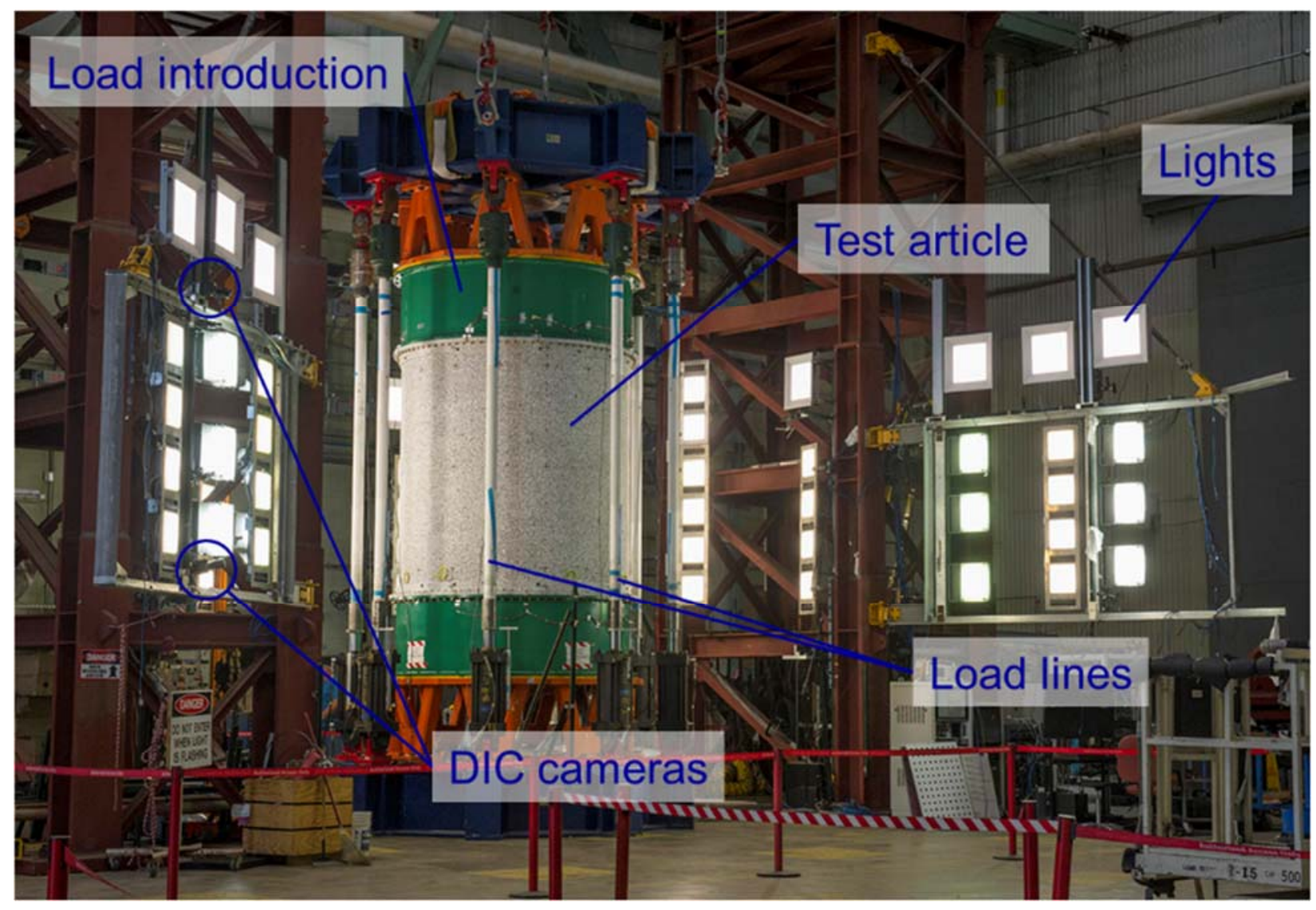

Figure 1. Eight-ft-diameter cylindrical test setup. 
Radial

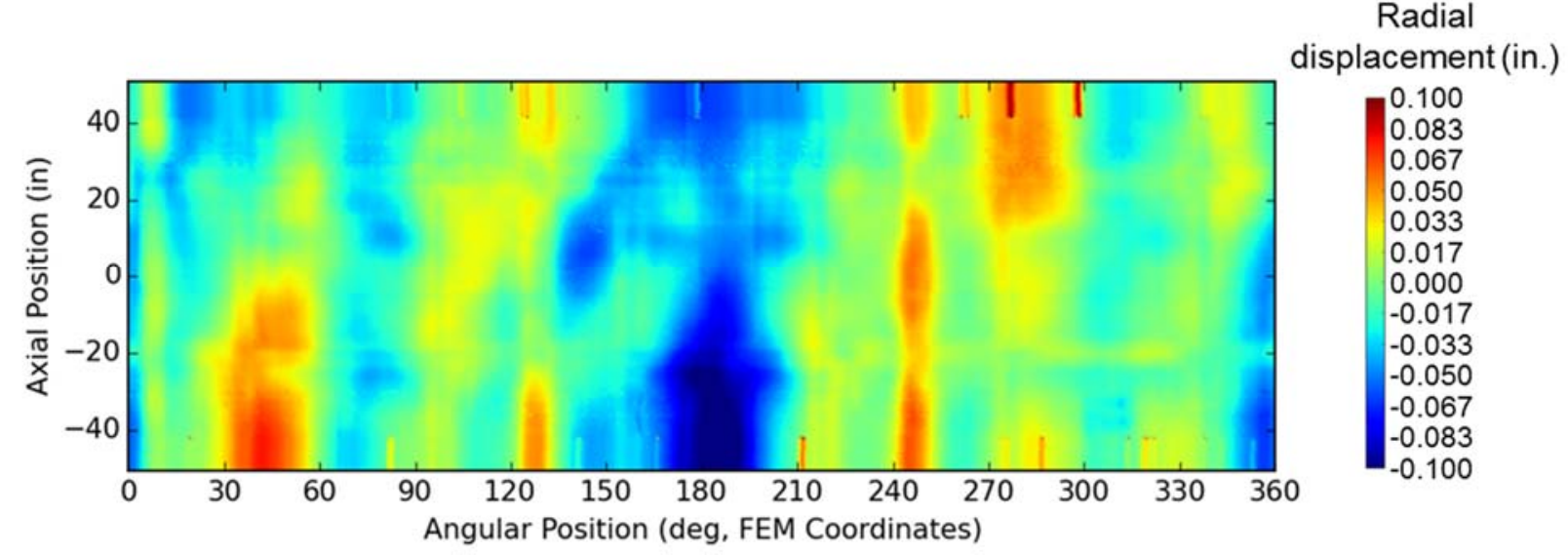

(a) Midsurface radial deviations

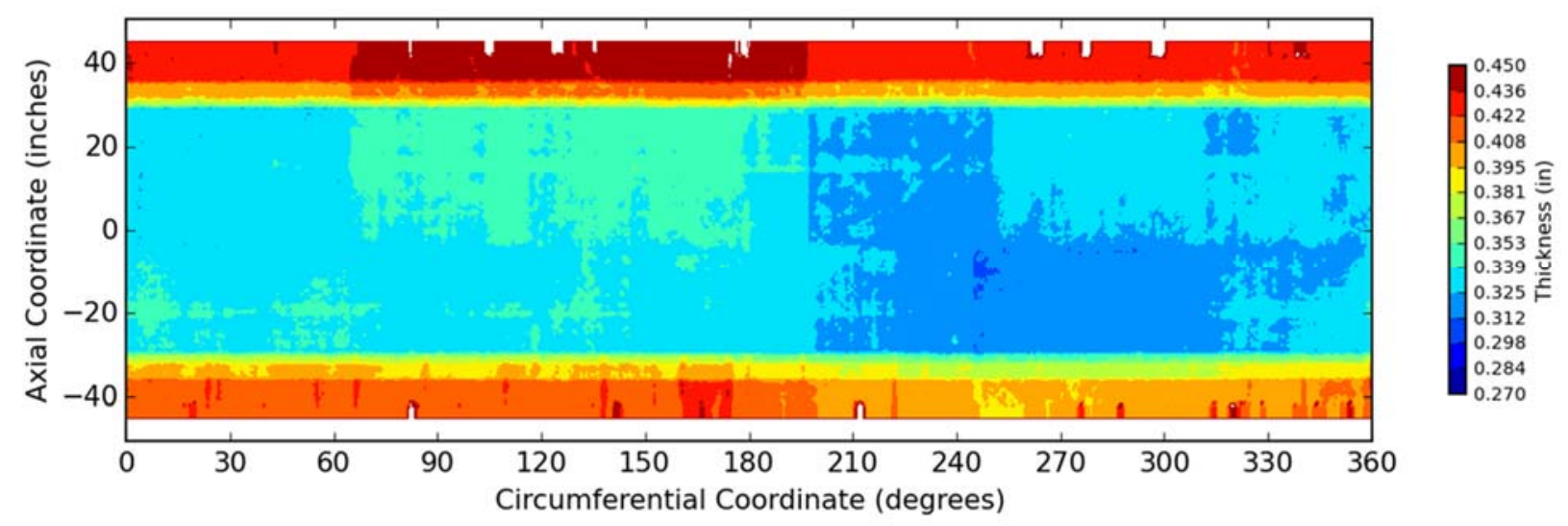

(b) Calculated thickness.

Figure 2. The (a) measured midsurface radial deviations from a best-fit cylinder and (b) calculated thickness. 


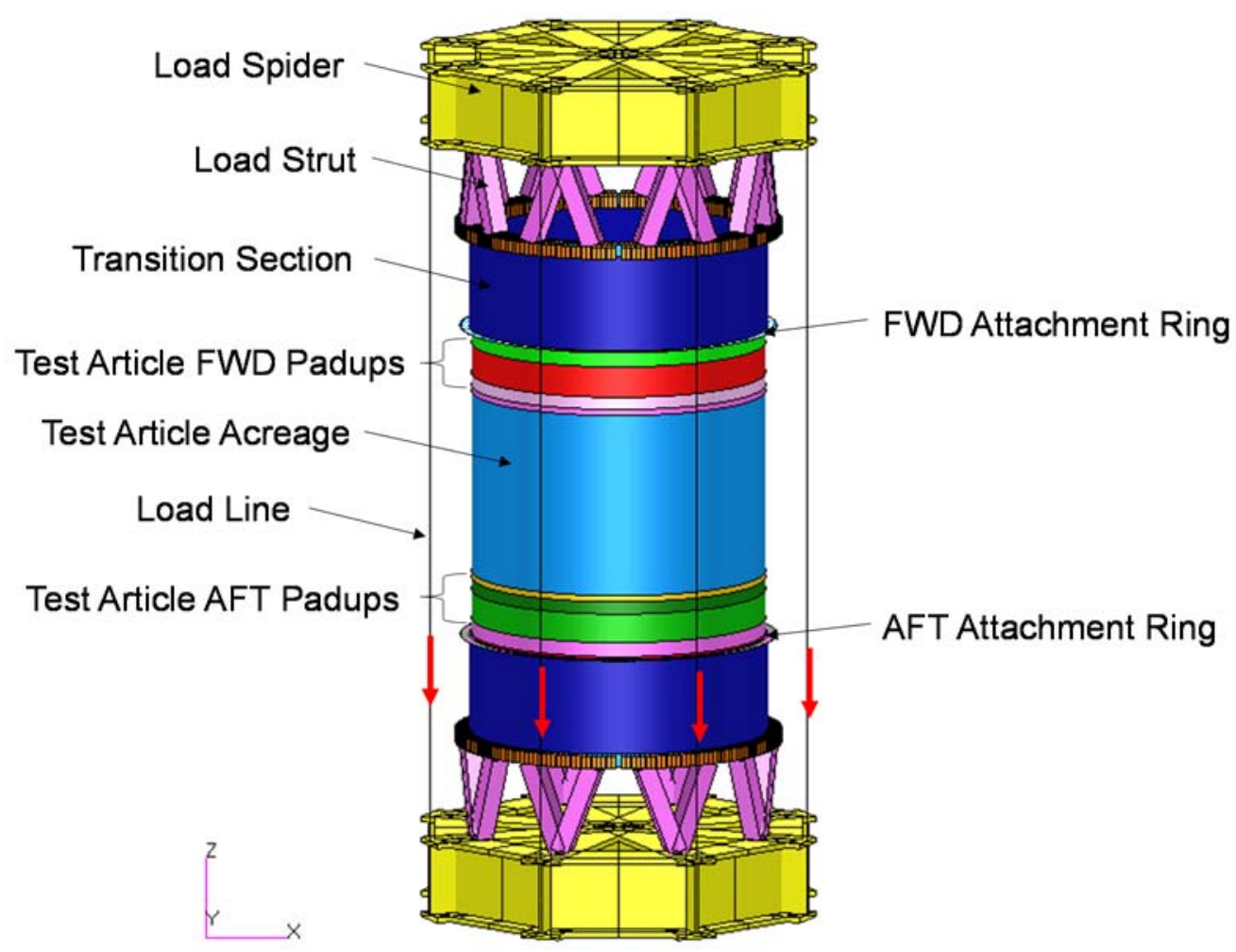

Figure 3. Finite-element model of CTA 8.1 test assembly. 


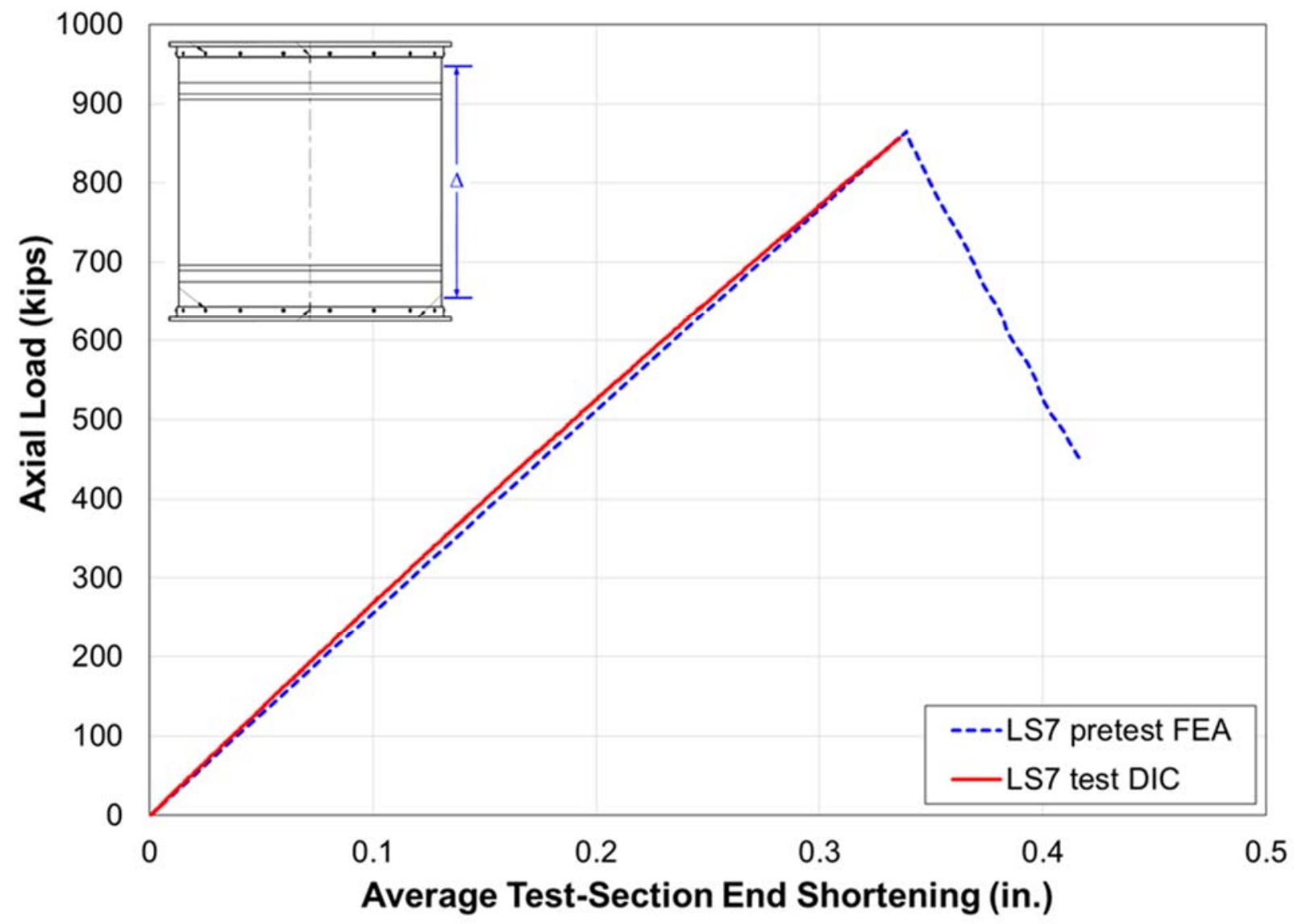

Figure 4. Load vs. average axial displacement curve for final test to failure (pretest correlation). 


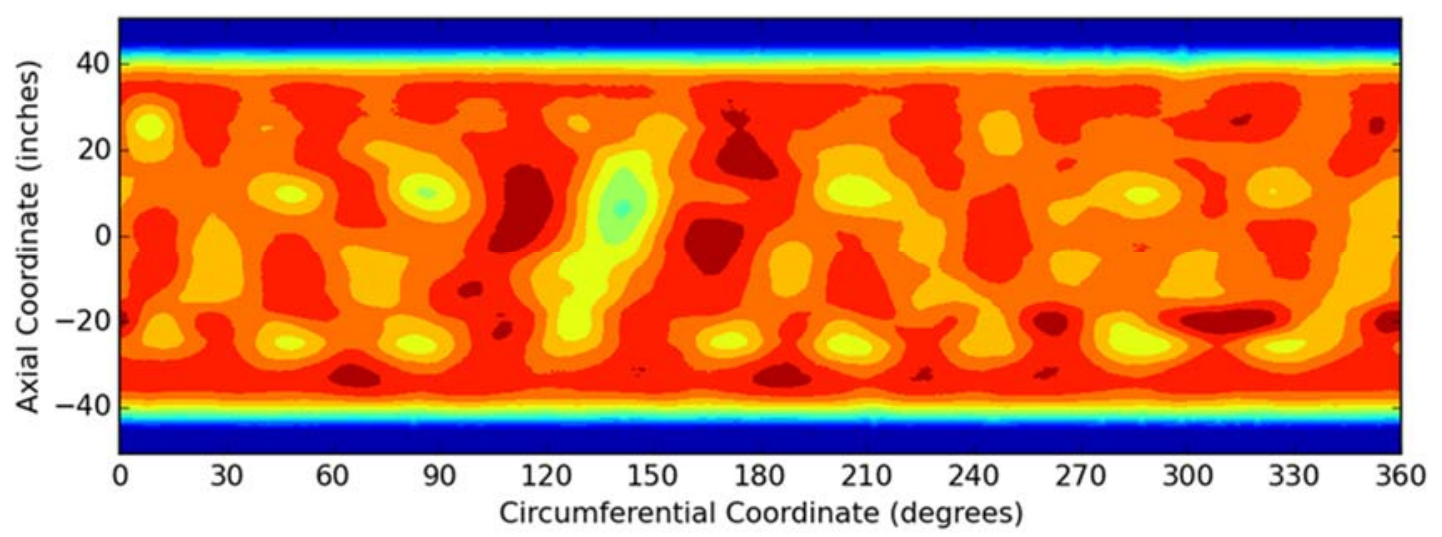

Radial

displacement, in.

0.0617

0.0566

0.0514

0.0462

0.0411

0.0359

0.0307

0.0255

0.0204

0.0152

0.0100

0.0049

$-0.0003$

(a) Pretest prediction

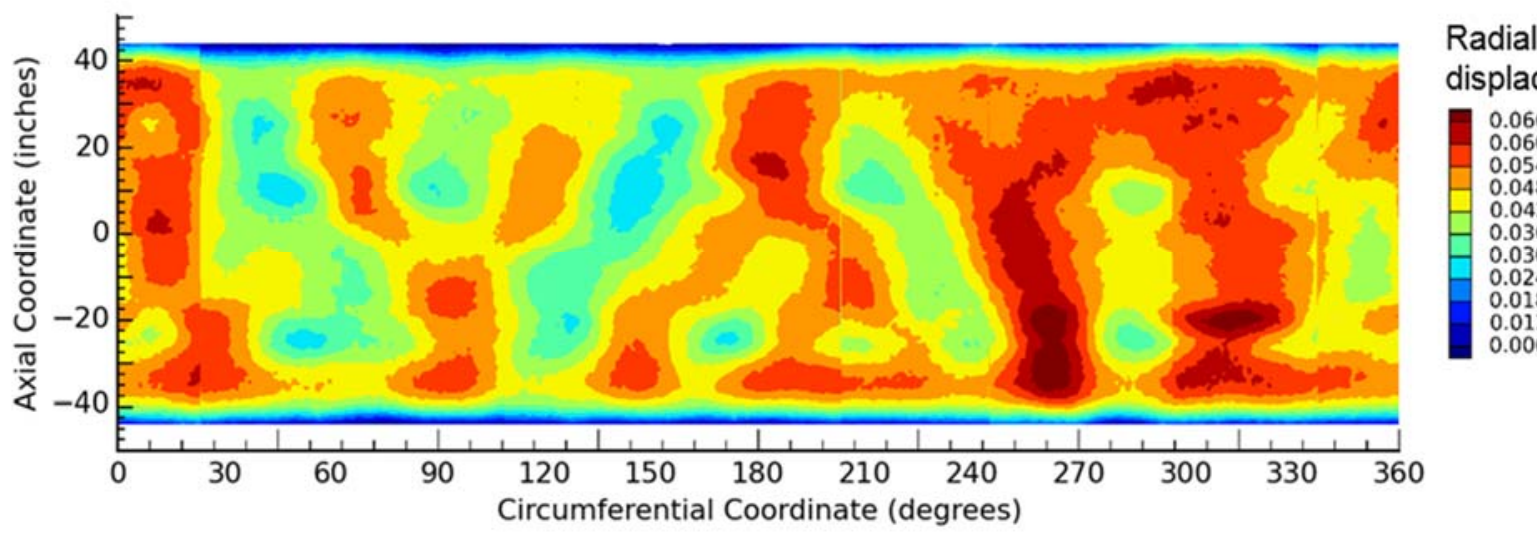

(b) Test

Figure 5. Radial displacements at 458,200 lb load. 


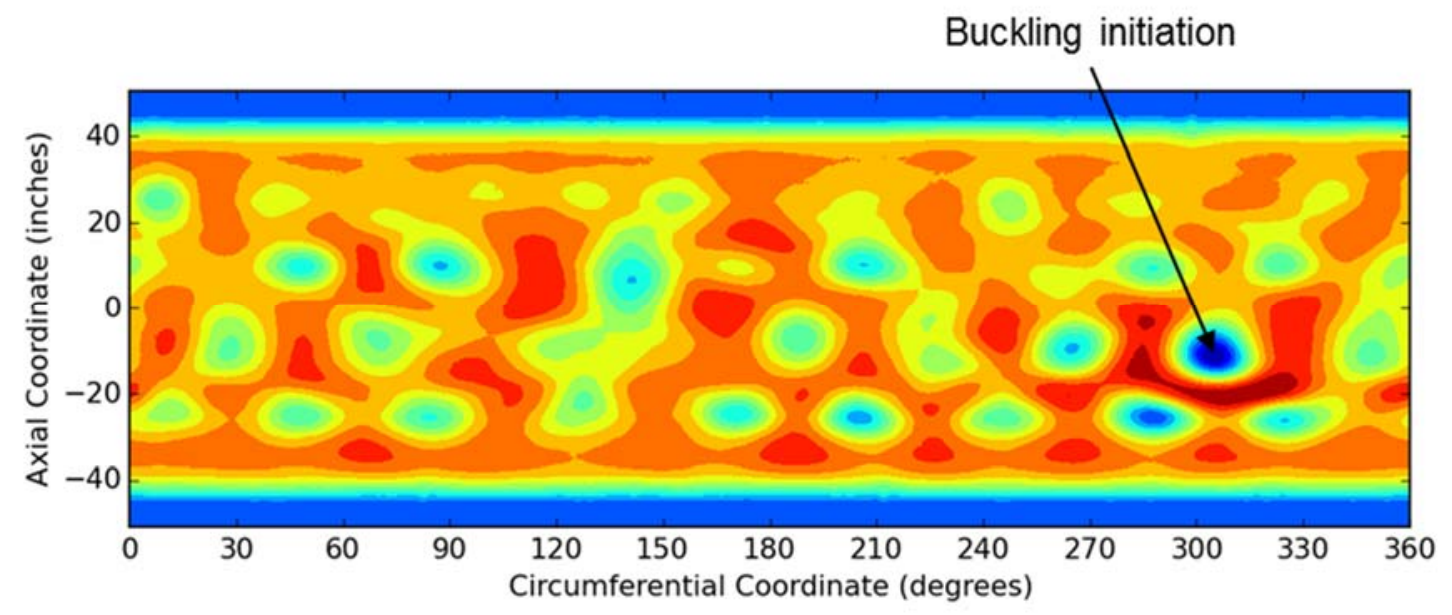

Radial

displacement, in.

0.1494

0.1339

0.1184

0.1030
0.0875

0.0720

0.0565

0.0410

0.0255

0.0100
-0.0054

$-0.0209$

$-0.0364$

(a) Pretest prediction

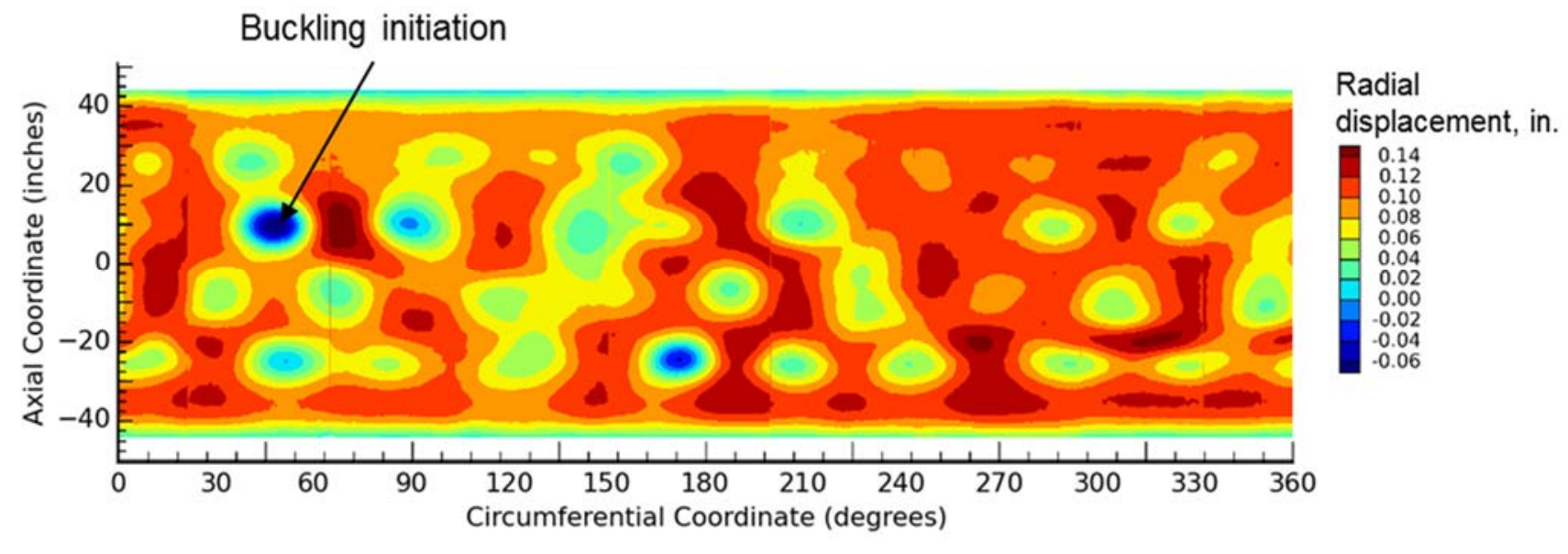

(b) Test

Figure 6. Radial displacements at incipient buckling. 


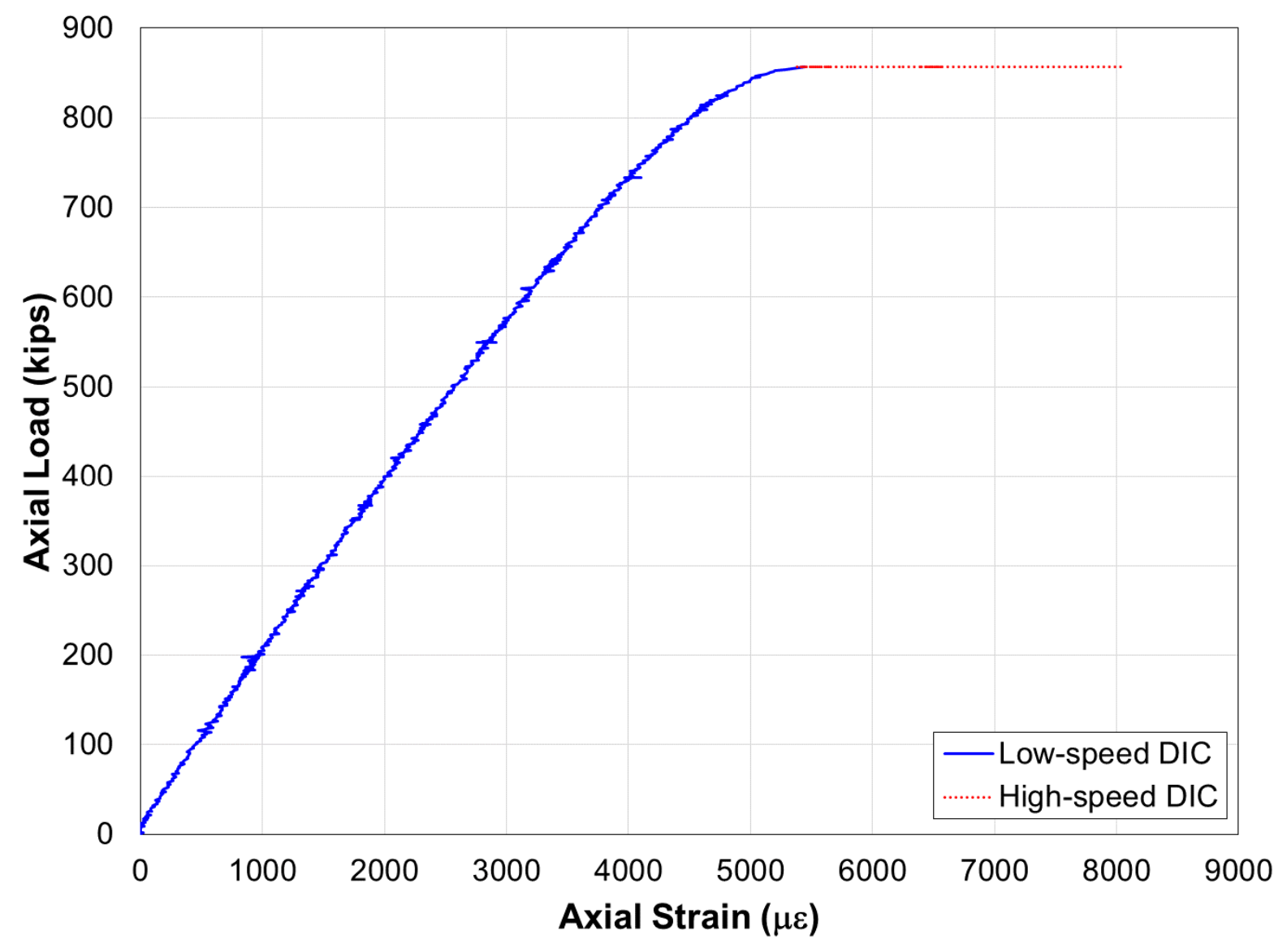

Figure 7. Experimental axial load vs. axial strain at the buckling initiation site (from DIC). 


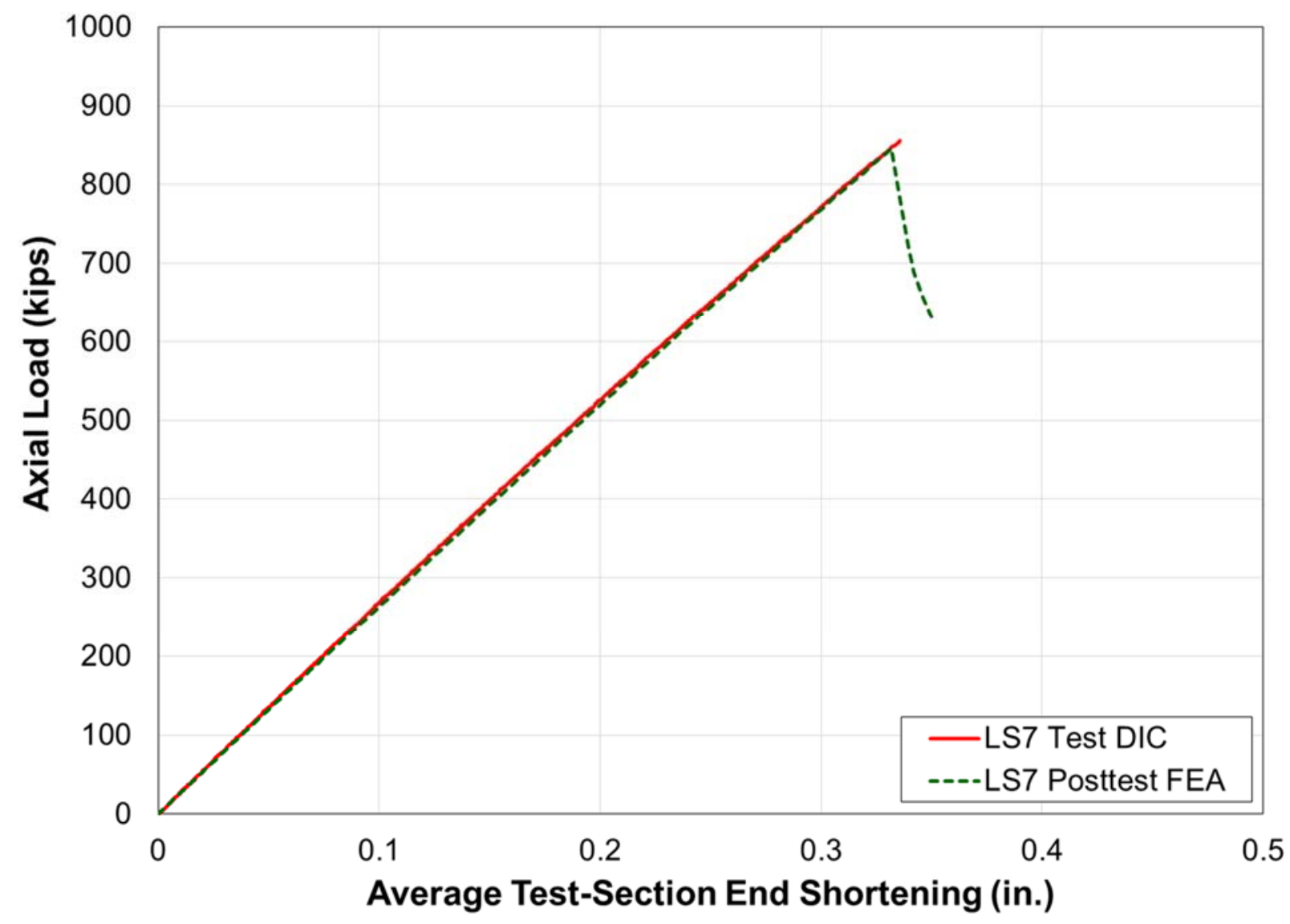

Figure 8. Load vs. average axial displacement curve for final test to failure (posttest correlation). 


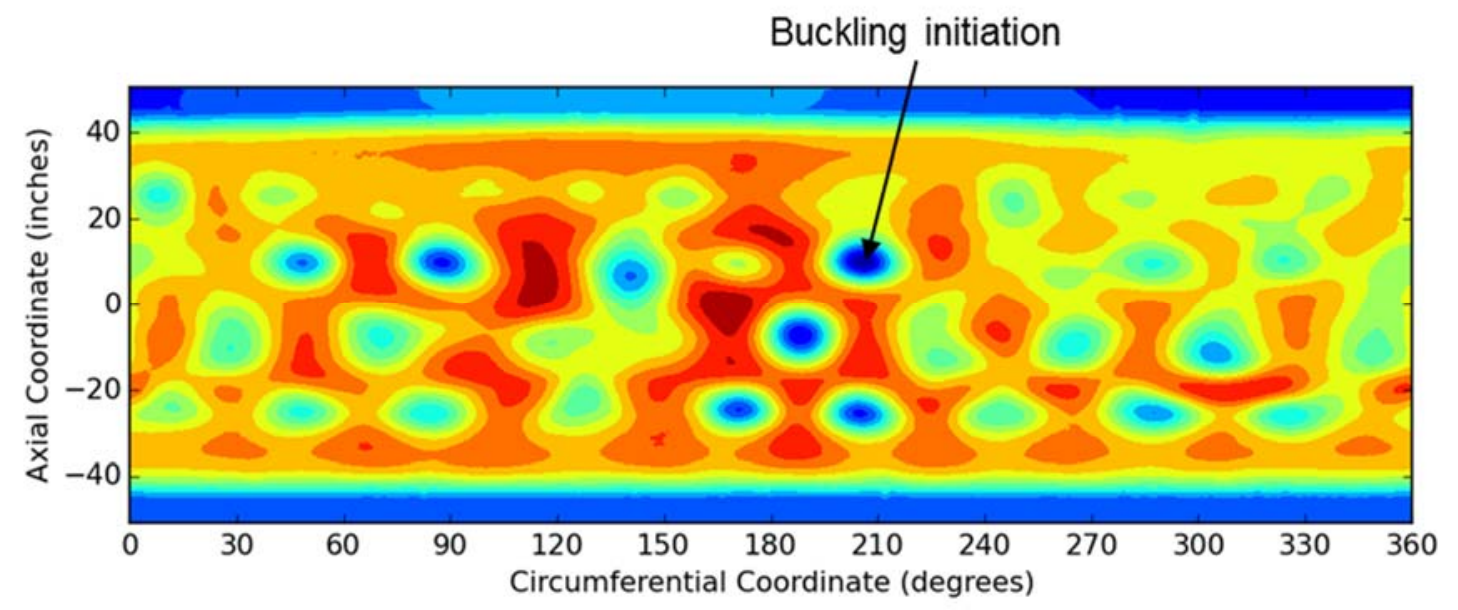

Radial displacement, in.

0.1485

0.1329

0.1172

0.1015

0.0859

0.0702

0.0546

0.0389

0.0233

0.0076

$-0.0081$

$-0.0237$

(a) Bending toward $135^{\circ}$

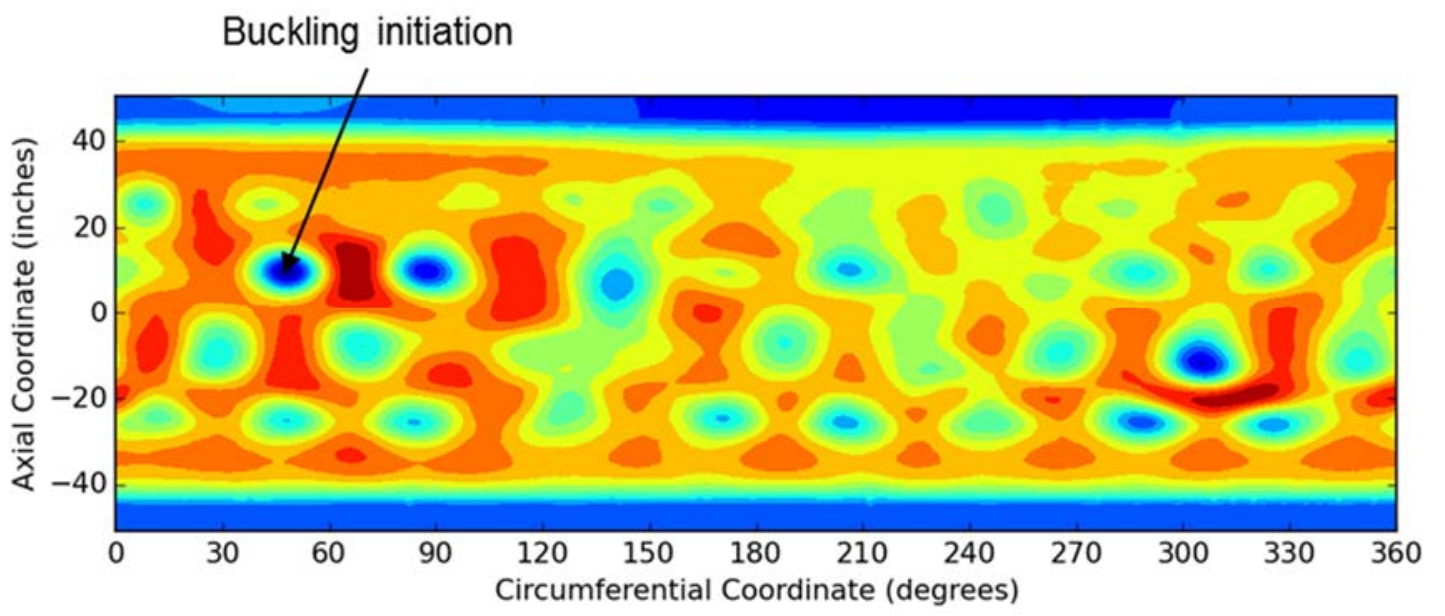

Radial

displacement, in.

0.1471

0.1321

0.1171

0.1021

0.0872

0.0722

0.0572

0.0422

0.0272

0.0122

$-0.0028$

$-0.0177$

0.0327

(b) Bending toward $45^{\circ}$

Figure 9. Predicted radial displacements at incipient buckling for combined compression and $3 \%$ bending toward (a) $135^{\circ}$ and (b) $45^{\circ}$. 